Short Communication

\title{
Morphofunctional characteristics of ACTH cells in middle-aged male rats after treatment with genistein
}

\author{
Verica Lj. Milošević*, Vladimir Z. Ajdžanović*, Branka T. Šošić-Jurjević, Branko R. Filipović, \\ Marjana P. Brkić, Nataša M. Nestorović and Milka I. Sekulić
}

Institute for Biological Research, "Siniša Stanković”, University of Belgrade, Serbia

\begin{abstract}
The soybean phytoestrogen, genistein, is increasingly consumed as an alternative therapeutic for age-related diseases. The aim of this study was to examine the morphofunctional characteristics of adrenocorticotrophic (ACTH) cells and blood concentrations of ACTH in sham-operated, orchidectomized and genistein-treated orchidectomized, 16-month-old Wistar male rats. Genistein $(10 \mathrm{mg} / \mathrm{kg} /$ day) was administered subcutaneously for three weeks, while the control groups received the vehicle alone. Orchidectomy and genistein treatment decreased the volume density of ACTH cells and reduced $(p<0.05)$ circulating ACTH concentrations in comparison with control groups. In conclusion, genistein modulated the morphofunctional features of ACTH cells and decreased blood ACTH levels.
\end{abstract}

Key words: ACTH — Genistein — Middle-age — Orchidectomy — Rats

Some plant derived compounds, structurally similar to endogenous mammalian hormones, can mimic or antagonize the actions of these hormones and, thereby, affect certain events controlled by the endocrine system (Adlercreutz and Mazur 1997). Genistein, an isoflavone from soybeans, has structural and functional similarity to $17 \beta$-estradiol (Setchell 1998) and acts as a phytoestrogen. It has significantly higher affinity for estrogen receptor $\beta$ than for estrogen receptor $\alpha$ (Kuiper et al. 1997). Genistein is also well known as a tyrosine kinase inhibitor (Akiyama et al. 1987). Nutritional supplements containing genistein are widely used as an alternative therapy for cardiovascular diseases, osteoporosis and cancer by people of advanced age. Data illustrating the effects of genistein on adrenocorticotrophic (ACTH) cells are rather scarce. It is known that various cytokines are involved in the regulation of ACTH secretion and that some synergism exists between cytokines and corticotrophin releasing hormone on stimulation of proopiomelanocortin (POMC) gene expression (Besedovsky and del Rey 1996; Katahira et al. 1998). As a potent tyrosine kinase inhibitor, genistein interrupts the

\footnotetext{
* These authors contributed equally to the paper.

Correspondence to: Verica Milošević, Institute for Biological Research "Siniša Stanković", 142 Despot Stefan Blvd., 11060 Belgrade, Serbia

E-mail: dimi@ibiss.bg.ac.yu
}

tyrosine phosphorylation cascade and inhibits stimulatory effects of cytokines on POMC gene transcription in vitro (Katahira et al. 1998). The present study was designed to evaluate the effects of subcutaneously applied genistein in a small therapeutic dose on morphometric and functional characteristics of ACTH cells in the pituitary gland of orchidectomized middle-aged male rats (animal model of the andropause). Orchidectomy was carried out with a view to annihilate the effects of endogenous sex steroids on the anterior pituitary.

The experiments involved 16-month-old male Wistar rats, which were bred in the Institute for Biological Research (Belgrade, Serbia), housed two per cage, exposed to a $12: 12 \mathrm{~h}$ light/dark cycle and kept at $22 \pm 2^{\circ} \mathrm{C}$. Two weeks before the experiment, the rats started to eat a soy-free diet (according to Picherit et al. 2000) prepared in cooperation with the Department of Nutrition, School of Veterinary Medicine (Belgrade, Serbia), and INSHRA PKB (Belgrade, Serbia), with corn oil as a fat source. Sham surgery and orchidectomy were performed under ketamine anaesthesia (ketamine hydrochloride $15 \mathrm{mg} / \mathrm{kg}$ b.w.; Richter Pharma, Wels, Austria). Sham-operated $(n=8)$ and orchidectomized rats were allowed to recover for 2 weeks. After recovery, the orchidectomized rats were divided into two groups of eight animals each. One group was subcutaneously treated with genistein (Nutraceutica, Monterenzio, Italy) in a dose of $10 \mathrm{mg} / \mathrm{kg}$ 
b.w. every day except on Sundays for 3 weeks. The other orchidectomized group and the sham-operated group were given the same volume $(0.5 \mathrm{ml})$ of vehicle alone. All animals were killed by decapitation $24 \mathrm{~h}$ after the last injection. The experimental protocols were approved by the Animal Care Committee of the Institute for Biological Research (Belgrade, Serbia) in conformity with the recommendations provided in the Guide for the Care and Use of Laboratory Animals (1996, National Academy Press, Washington D.C.).

Pituitary glands were excised, weighed in air, fixed in Bouin's solution and embedded in paraplast. Serial, $5 \mu \mathrm{m}$ thick tissue sections were treated with xylol and serial alcohol. Pituitary ACTH cells were localized by the peroxidase-antiperoxidase-complex method of Sternberger et al. (1970). Measurements were made on the widest portion of the pituitary gland and immunocytochemically labelled ACTH cells were analyzed using the M42 multipurpose test system by Weibel (1979). Concentrations of ACTH were determined in undiluted plasma by ELISA (Biomerica, Hannover, Germany). Morphometric and hormonal level data obtained for each group were averaged and standard deviations of the means were calculated. ANOVA (one-way analysis of variance), followed by Duncan's multiple range test was used for statistical comparisons between the groups. A probability value of $5 \%$ or less was considered statistically significant.

The data on absolute and relative pituitary weights in all experimental groups are summarized in Table 1 . The relative pituitary weight was increased $(p<0.05)$ by $15 \%$ in the orchidectomized and $32 \%$ in the orchidectomized genisteintreated group, compared to the sham-operated group.

ACTH immunoreactive cells in the pituitary pars distalis of the sham-operated male rats were localized in close contact with blood capillaries. They were ovoid or irregular in shape with prominent, often eccentrically located nuclei (Fig. 1A). ACTH immunoreactive cells in orchidectomized and orchidectomized genistein-treated animals were smaller, often pycnotic and darkly stained (Fig. 1B,C) in comparison with sham-operated animals.

The volume $\left(\mu \mathrm{m}^{3}\right)$ of ACTH cells was decreased $(p<0.05)$ by 11 and $13 \%$ in orchidectomized and orchidectomized genistein-treated rats, respectively, in comparison with sham-operated animals (Table 1). The volume density (\%) of these cells in the orchidectomized and orchidectomized genistein-treated groups was 16 and $48 \%$ lower $(p<0.05)$ respectively, than in the sham-operated group (Table 1 ). In comparison to the orchidectomized group, the volume density of ACTH cells had decreased $(p<0.05)$ by $38 \%$ in the orchidectomized genistein-treated group (Table 1). The plasma level of ACTH in orchidectomized males was $14 \%$ higher $(p<0.05)$ but in orchidectomized genistein-treated rats $66 \%$ lower $(p<0.05)$ than in sham-operated males (Fig. 2). Compared to the orchidectomized group, the plasma
A

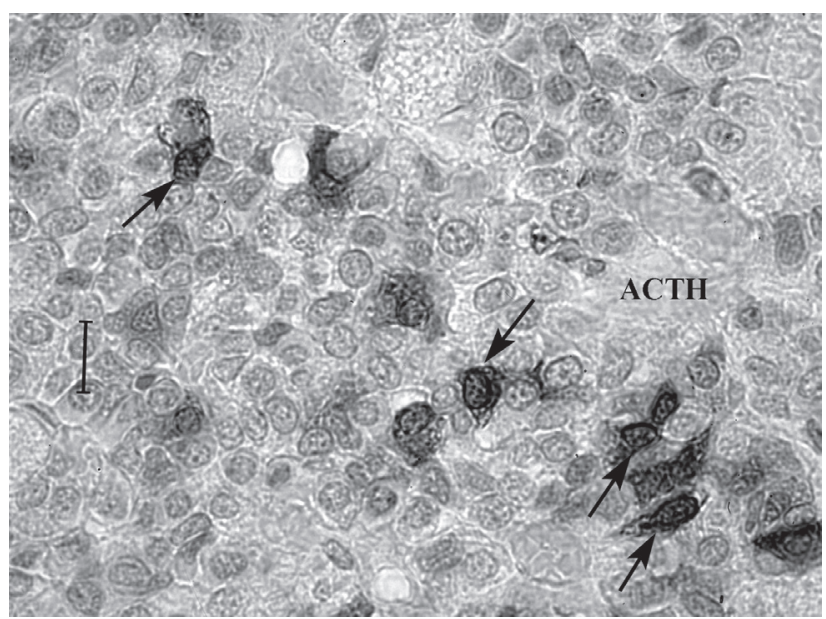

B

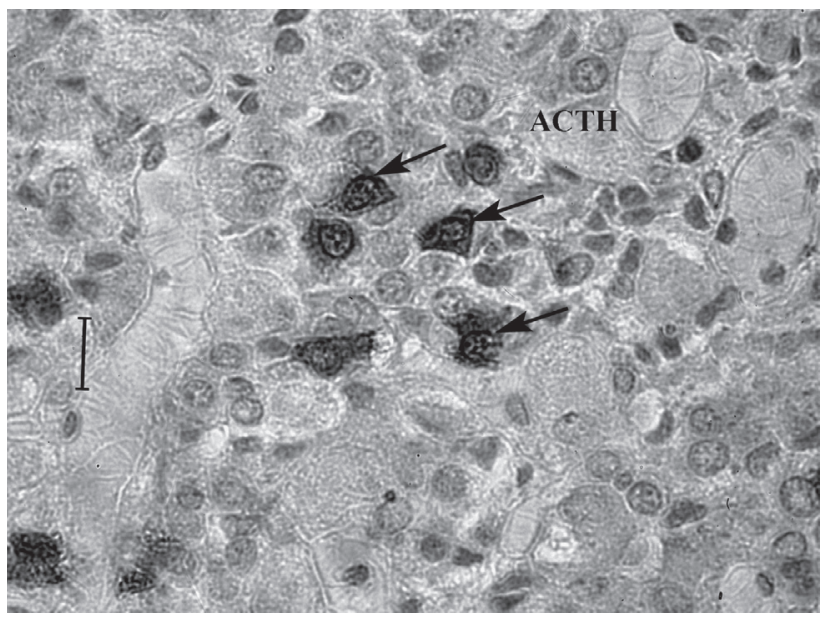

\section{C}

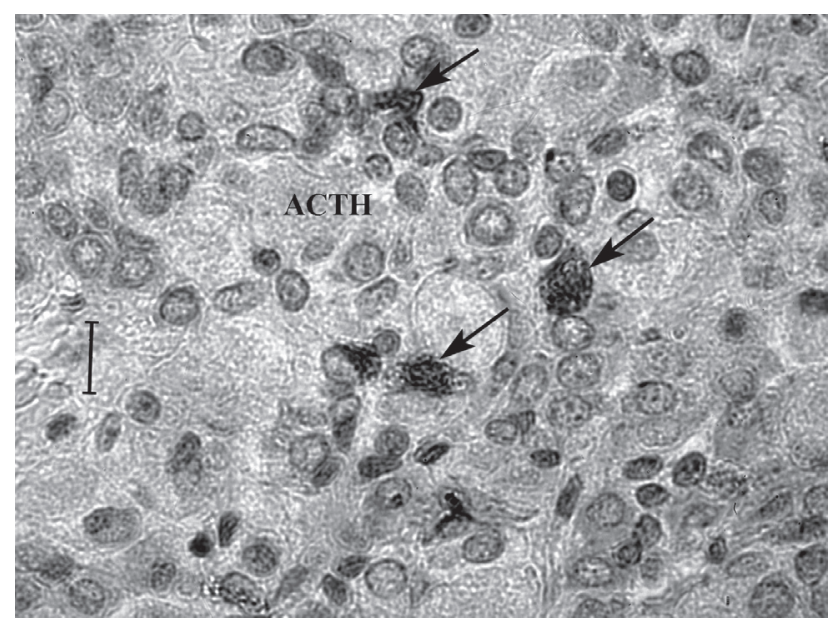

Figure 1. Immunopositive adrenocorticotrophic (ACTH) cells in pars distalis of the pituitary gland from: A. sham-operated rats; B. orchidectomized rats and C. orchidectomized genistein-treated rats. (Peroxidase-antiperoxidase complex, bar $=40 \mu \mathrm{m}$ ). 
Table 1. Effects of orchidectomy (Orx) and Orx followed with genistein (Orx $+\mathrm{G})$ treatment on absolute and relative pituitary weight and morphometric parameters of the adrenocorticotrophic (ACTH) cells in middle-aged male rats

\begin{tabular}{|l|c|c|c|c|}
\hline Group & $\begin{array}{c}\text { Absolute pituitary } \\
\text { weight }(\mathrm{mg})\end{array}$ & $\begin{array}{c}\text { Relative pituitary weight } \\
(\mathrm{mg} \%)\end{array}$ & $\begin{array}{c}\text { Volume of the ACTH cells } \\
\left(\mu \mathrm{m}^{3}\right)\end{array}$ & $\begin{array}{c}\text { Volume density of the } \\
\text { ACTH cells }(\%)\end{array}$ \\
\hline Sham & $17 \pm 1.7$ & $2.2 \pm 0.1$ & $912.1 \pm 54.5$ & $20.1 \pm 1.1$ \\
\hline \multirow{2}{*}{ Orx } & $16.6 \pm 1.4$ & $2.5 \pm 0.2^{\mathrm{a}}$ & $813.8 \pm 49.8^{\mathrm{a}}$ & $16.9 \pm 0.7^{\mathrm{a}}$ \\
$(-2 \%)$ & $(+15 \%)$ & $(-11 \%)$ & $\begin{array}{c}(-16 \%) \\
\text { Orx+G }\end{array}$ \\
\hline \multirow{2}{*}{ (19.2 } & $(+13 \%)$ & $\begin{array}{c}2.9 \pm 0.2^{\mathrm{a}} \\
(+32 \%)\end{array}$ & $\begin{array}{c}792.5 \pm 7.4^{\mathrm{a}} \\
(-13 \%)\end{array}$ & $\begin{array}{c}10.4 \pm 0.9^{\mathrm{a}, \mathrm{b}} \\
(-48 \%) ;(-38 \%)\end{array}$ \\
\hline
\end{tabular}

All values are means $\pm \mathrm{SD}, n=8 ;^{\mathrm{a}} p<0.05$ in comparison with the sham-operated group; ${ }^{\mathrm{b}} p<0.05$ in comparison with the orchidectomized group.

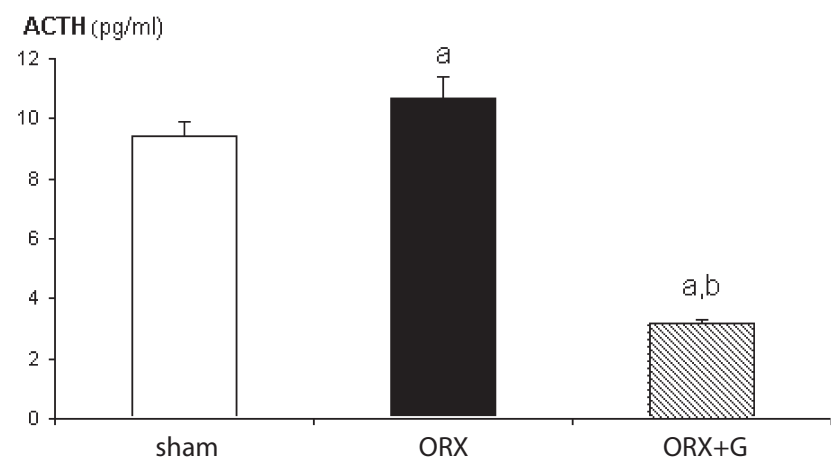

Figure 2. Plasma levels of ACTH in middle-aged male rats. The values are means $\pm \mathrm{SD}, n=8$; ${ }^{\mathrm{a}} p<0.05$ in comparison with the sham-operated group; ${ }^{\mathrm{b}} p<0.05$ in comparison with the orchidectomized group.

level of ACTH in the orchidectomized genistein-treated group had declined $(p<0.05)$ by $70 \%$ (Fig. 2 ).

The presented results clearly demonstrate increases in the relative pituitary weight in orchidectomized and orchidectomized genistein-treated rats in comparison to the sham-operated animals. Delclos et al. (2001) observed a trend towards increased relative pituitary weight in both male and female pups whose dams had received high doses of genistein. Lasting toxicology and carcinogenesis feed studies of genistein (see in References: NTP, 2008), also, indicated significant increasement of pituitary gland weight in female rats. The volume of ACTH cells and their volume density as well as plasma ACTH concentration significantly decreased after orchidectomy and genistein treatment. When compared to the group where only orchidectomy was performed, the decline in plasma ACTH level was even greater. In addition, histological analysis revealed more intense immunostaining of ACTH cells in the orchidectomized genistein-treated group. We believe that genistein treatment led to inhibition of ACTH synthesis. Redei et al. (1994) reported that estrogen replacement lowered POMC mRNA level and the ACTH response to repeated stressful stimuli in ovariect- omized rats. In this study, genistein, a compound with weak estrogenic activity, gave sign of the same effect. It has been shown that various cytokines generated during stress are involved in regulation of the hypothalamo-pituitary-adrenal axis, establishing the concept of immune-neuroendocrine interaction (Besedovsky and del Rey 1996). In some cases, cytokines may directly affect ACTH cells in the anterior pituitary (Naito et al. 1989; Hanisch et al. 1994). Establishing the exact role of cytokines in POMC gene transcription and ACTH production requires additional studies. Katahira et al. (1998) suggested that genistein, as a tyrosine kinase inhibitor, significantly decreased the stimulatory effects of cytokines on POMC gene transcription in vitro. Also, an estrogenic mechanism based, carcinogenic activity of genistein in female rat mammary glands and pituitaries was observed (see in References: NTP, 2008). In the same study, there was no evidence about carcinogenic activity of genistein in male rat pituitaries. We assume that genisteinmediated estrogen receptor independent mechanisms, i.e. non-functional tyrosine kinase enzyme-substrate complexes production, are predominant in ACTH cells. Supplementary studies, investigating estrogen receptor distribution in different pituitary cell populations of both sexes, are required for interpretation of our results.

In conclusion, our study showed that in orchidectomized middle-aged male rats, chronic subcutaneous genistein administration in a small dose decreased the morphofunctional characteristics of ACTH cells.

Acknowledgement. This work was supported by the Ministry for Science of Serbia, grant number 143007B.

\section{References}

Adlercreutz H., Mazur W. (1997): Phyto-oestrogens and Western diseases. Ann. Med. 29, 95-120

Akiyama T., Ishida J., Nakagawa S., Ogawara H., Watanabe S., Itoh N., Shibuya M., Fukami Y. (1987): Genistein, a specific inhibitor of tyrosine-specific protein kinases. J. Biol. Chem. 262, 5592-5595 
Besedovsky H. O., del Rey A. (1996): Immune-neuro-endocrine interactions: facts and hypothesis. Endocr. Rev. 17, 64-102

Delclos K. B., Bucci T. J., Lomax L. G., Latendresse J. R., Warbritton A., Weis C. C., Newbold R. R. (2001): Effects of dietary genistein exposure during development on male and female CD (Sprague-Dawley) rats. Reprod. Toxicol. 15, 647-663

Hanisch U. K., Rowe W., Sharma S., Meaney M. J., Quirion R. (1994): Hypothalamic-pituitary-adrenal activity during chronic central administration of interleukin-2. Endocrinology 135, 2465-2472

Katahira M., Iwasaki Y., Aoki Y., Oiso Y., Saito H. (1998): Cytokine regulation of the rat proopiomelanocortin gene expression in AtT-20 cells. Endocrinology 139, 2414-2422

Kuiper G. G., Carlsson B., Grandien K., Enmark E., Haggblad J., Nilsson S., Gustafsson J. A. (1997): Comparison of the ligand binding specificity and transport tissue distribution of estrogen receptors alpha and beta. Endocrinology $138,863-870$

Naito Y., Fukata J., Tominaga T., Masui Y., Hirai Y., Murakami N., Tamai S., Mori K., Imura H. (1989): Adrenocorticotropic hormone-releasing activities of interleukins in a homologous in vivo system. Biochem. Biophys. Res. Commun. 164, 1262-1267

NTP Toxicology and Carcinogenesis Studies of Genistein (CAS No. 446-72-0) in Sprague-Dawley Rats (Feed Study)
(2008): Natl. Toxicol. Program Tech. Rep. Ser. 545, $1-240$

Picherit C., Coxam V., Bennetau-Pelissero C., Kati-Coulibaly S., Davicco M. J., Lebecque P., Barlet J. P. (2000): Daidzein is more efficient than genistein in preventing ovatiectomyinduced bone loss in rats. J. Nutr. 130, 1675-1681

Redei E., Li L., Halasz I., McGivern R. F., Aird F. (1994): Fast glucocorticoid feedback inhibition of ACTH secretion in the ovariectomized rat: effect of chronic estrogen and progesterone. Neuroendocrinology 60, 113-123

Setchell K. D. (1998): Phytoestrogens: the biochemistry, physiology and implications for human health of soy isoflavones. Am. J. Clin. Nutr. 68 (Suppl.), 1333-1346

Sternberger L. A., Hardy P. H. J., Cuculius J. J., Meyer H. G. (1970): The unlabelled antibody enzyme method of immunohistochemistry. Preparation and properties of soluble antigen-antibody complex (horseradish peroxidase-antihorseradish peroxidase) and its use in identification of spirochetes. J. Histochem. Cytochem. 18, 315-333

Weibel E. R. (1979): I. Practical methods for biological morphometry. In: Stereological Methods. Vol. 1, Academic Press, New York

Received: December 10, 2008

Final version accepted: February 5, 2009 